existence of tubercles within the encephalon could not have been diagnosed, nor justly suspected, until the irritation they occasioned gave rise to symptoms of cerebral disorder. There may, however, sometimes be good grounds for fearing their presence before symptoms so severe, as in the present case, arise, and we should never forget the possibility, in interpreting our earlier symptoms. But in reference to the state of the lungs a different answer must be given. In all probability their condition could have been satisfactorily made out. One sign, indeed, was evident after death in a marked dulness on percussion, especially over the upper part of the chest: and there can be little doubt that changes in the respiratory murmur \&c. might have been detected, sufficient to have confirmed a diagnosis; and in such a state of things my feeling is, that no operation would be justifiable. The issue of the case was just what $I$ expected from the moment that cerebral symptoms became distinct; for I had little doubt that the meningitis was due to the irritation of tubercles in or upon some portion of the brain. And the prognosis in such a disease, where there is good ground for suspecting a tuberculous origin, must be always unfavourable.

London, 1848.

REPORT OF A CASE OF

\section{DISLOCATION OF THE THIGH FORWARDS, ON THE OS PUBIS.}

By G. YEATES HUNTER, Esq., M.R.C.S., \&c., Margate.

Dislocation of the os femoris, on the horizontal ramus of the os pubis, is of very rare occurrence, and has, perhaps, seldom happened to a person seventy-seven years of age, at which extended period of life fracture of the cervix femoris is the more general result of accident.

April 20th.-Thomas C-C, of Rancorn, aged seventyseven years, while repairing the chimney of a small freehold, fell, with the ladder, from the kitchen roof, and, in falling, struck his thigh against a rail; when taken up by the neighbours, his left thigh was found to be serionsly injured. My assistant, Mr. Wm. Henry Thornton, being summoned to his assistance, was, with my son, promptly in attendance. Mr. Thornton readily detected dislocation of the os femoris on the horizontal ramus of the pubes, and having failed to reduce it by fixing the pelvis, and extension with towels, sent home for Weiss's dislocation case, with which I quickly joined him. The patient was placed upon a mattrass on his sound side, and the apparatus having been properly applied, cautious and gradual extension was made in the usual manner, during which, I having lifted the head of the bone from its position on the ramus, it quickly passed into the acetabulum with a smartish snap.

I may observe that the patient is a short, compact, and, for his age, a muscular man; that the dislocation was more readily reduced than might have been expected; and that the poor man is going on well, no untoward symptoms having supervened.

Margate, May, 1848 .

\section{LOCAL AN ESTHESIA;}

NOTES ON ITS ARTIFICIAL PRODUCTION BY CHLOROFORM ETC. IN THE LOWER ANIMALS, AND IN MAN.

BF J. Y. SIMPSON, M.D., F.R.S.E.,

PROFESSOR OF MIDWIFERY IN THE UNIVERSITY OF EDINBURGH.

A FEw months ago, I published some remarks, with the object of proving that the artificial production of a state of general anæesthesia before the performance of surgical operations, was not altogether an idea of modern times.* I showed that Pliny, Apuleius, and other early writers, aver that such a state of general anæesthesia can be produced by using mandragore; and that, in the thirteenth century, Theodoric had published a receipt for producing it by the inhalation of vapours arising from the watery extracts of various narcotic herbs. In our own days, this receipt of Theodoric's has been apparently found quite sufficient for the purpose by Dauriol.

The ancients seem also to have entertained the idea of the possibility of producing a state of local and limited anæsthesia in any part to be operated upon. Dioscorides, who repeatedly mentions the production of general anæesthesia by mandragore, states it as a matter of report, that local anæesthesia in a part was capable of being produced by the application of the
Memphian stone. "The Memphian stone (says he) is found in Egypt, near Memphis, of the size of a calculus, fatty, and of different colours. They say that this, when bruised and spread over parts that are to be cut or cauterized, without danger, so obtunds their sensibility, that they do not feel pain," (Hoc tradunt trito et illito partes quæ urendæ vel secandæ sunt citra periculum ita obstupescere, ut non sentiant cruciatum.)*

Whilst we may entirely doubt that local anæsthesia was capable of being produced by such an apocryphal application as the above, the passage is curious, as evidence that the idea of obtunding a single part of the body against the pain of an operation was not unknown or unthonght of in former times. Nay, many old authorities believed that against the fire ordeal any part of the body could be so protected and defended by previous applications, that the human hand, for instance, should not feel the contact of the red-hot iron. 'The writings of Salverte and Beckmann contain ample notices on this disputed question. Upwards of half a century ago, Dr. Moore ingeniously proposed to effect a local anæesthesia of any limb that was to be operated upon by the surgeon, by previously compressing with tourniquets and pads the nervous trunks going to that limb; and he has left us one interesting account of a case of amputation at St. George's Hospital, in which this plan was tried with partial success by John Hunter.

The possible production of local anæsthesia by this or by other means, is certainly an object well worthy of study and attainment. Surgeons everywhere seem to be more and more acknowledging the facility, certainty, and safety, with which the state of general anæsthesia can be produced at will before operating, as well as the moral and professional necessity of saving their patients from all unrequisite pain. But if we could by any means induce a local anæsthesia, without that temporary absence of consciousness which is found in the state of general anæsthesia, many would regard it as a still greater improvement in this branch of practice. If a man, for instance, could have his hand so obtunded that he could see, and not feel, the performance of amputation upon his own fingers, the practice of anæsthesia in surgery would, in all likelihood, advance and progress even still more rapidly than it has done.

In the following remarks, it is my object to state the results of a number of experiments which I have performed, first, upon the lower animals, and secondly, upon man, with a view to the possibility of the production of such a state of local anæsthesia, by the application of chloroform and other anæsthetic agents to individual parts of the body.

\section{1.-Production of Local Ancesthesia in the Lover Animals.}

At a meeting of the Medico-Chirurgical Society of Edinburgh, held on the 17th March, I took occasion to state that I had successfully chloroformed several of the lower animals, as annelida, crustacea, fishes, \&c.; that in some, and more especially in the common earthworm, (lumbricus terrestris) I had been able to produce local anzsthesia by applying the chloroform vapour locally; and had thus, at will, rendered anæsthetic individual parts and portions of the worm, as the head merely, or the tail merely, or the middle part of the worm merely, the head and tail remaining unaffected. At the same time I recapitulated what I had stated at one of the February meetings of the Society, that in the human subject local anæsthesia of a portion of the gums could be produced by rubbing the part with hydrocyanic acid. After the date of the above meeting, I was led to make some additional experiments upon the possible production of local anresthesia in man; and in reporting the proceedings of the preceding sederunt of the Society in the last number of the Monthly Journal of Medical Science, the editor has stated, in a short foot-note, some of the results of these experiments upon the human subject.-(See Monthly Journal, No. xci. p. 48.)

Nothing could be more curious or satisfactory than the experiments alluded to on the production of local anesthesia by the local application of chloroform-vapour to different parts of the body of the earthworm. The resulting degree of local anzsthesia in the part exposed, is generally, in the course of two or three minutes, most complete, as regards both sensation and motion. In fact, after being sufficiently exposed, the chloroformed portion of the animal is quite flat and flaccid, does not move under any irritation, and can be doubled and twisted up upon itself like a piece of loose wetted cord If the part paralyzed by the chloroform is small, it will be dragged along by the movements of the other unaffected por-

* Monthly Journal of Medical Science for December, 1847-8, p. 4501 . 
tions of the worm. Commonly, in the course of a few minutes, it gradually regains its powers of motion, and its irritability and contraction under stimuli.

The easiest method of performing this experiment, is to place a small quantity of chloroform in the bottom of a tumbler, paste over the month of it a covering of paper, and to make an aperture in this covering sufficient only to admit the portion of the animal that is to be chloroformed. When held in this position, the part of the animal below the paper, and exposed to the vapour of chloroform, is generally thrown into violent movements for a minute or two before the state of anæsthesia supervenes. I have repeated the same experiment with the vapours of sulphuric ether, and of bi-sulphuret of carbon.

I have tried the same experiment, with the same result, apon the medicinal leech.

The results were, if possible, still more marked in one of the articulata that was submitted to experiment. A small centipede (iulus sabulosus?) was rendered completely anæsthetic and motionless in the posterior segments of the body, by exposing that part alone, for a few minutes, to the vapour of chloroform. The five or six last rings of the centipede, with the suspended and motionless feet attached to them, were, for a short time afterwards, dragged about in a sort of paraplegic state, by the $e^{z}$ brisk and lively movements of the anterior and not anosthetic portion of the animal. Betimes, however, each segment, with its corresponding feet, regained its power of motion, and this in regular order from before backwards.

By immersing the tail of the water-newt in chloroform vapour, the sensibility and motions of that part were rapidly destroyed, and returned a few minutes afterwards. By a longer degree of immersion of the tail alone, the whole animal became anæsthetic, and in several experiments it was found possible, but difficult, to give the animal in this way a fatal dose of the vapour.

The hind leg of the frog becomes anæsthetic when exposed for four or five minutes to the vapour of chloroform. Imme diately after it drags the limb in progressing, and bears, apparently without feeling, pricking and irritation of it; but a galvanic current passed through it excites both sensation and motion. In one case the motory power of the limb was not completely restored at the end of the third day. No effect appeared to result from keeping the hind leg of the frog immersed in strong tincture of Indian hemp.

One of the hind legs of a healthy active rabbit was confined in a large bladder containing the vapour of chloroform. At the end of an hour the common sensibility of the limb to pinching and squeezing was much impaired; but still a current of galvanism passed from side to side throngh it, produced crying and signs of pain. The power of moving the limb seemed impaired.

The hind leg of a guinea pig similarly treated, exhibited the same phenomena at the end of an hour, but the anæesthesia was more complete. The skin of the leg was red and congested.

The posterior extremities and pelvis of a strong gninea pig were enclosed in a bag containing the vapour of chloroform. At the end of an hour no signs of pain conld be extracted by pinching and squeezing either limb, and a current of galvanism passed through a hind leg evidently caused much less pain than when the same current was passed through a fore leg. The whole hinder parts were very red and congested. The animal was also in some degree paraplegic, and dragged itself along by strong efforts with its anterior limbs.

In the last number of Tre Lancet, Mr. Nunneley, of Leeds, has published some interesting remarks on the subject of the artificial production of local anæesthesia. Mr. Nunneley states that chloroform and other amasthetic agents can, he believes, be applied locally to a part to produce local anzesthesia, the sensorium being unaffected, consciousness beins retained, and the limbs and other parts not being subjected to the action of the anresthetic agent, retaining their usual anæsthetic condition. His opinions regarding the supposed value and safety of this new mode of administering anæesthetic agents had been formed by $M x$. Nunneley on the results of experiments. By the local application of chloroform to the limbs of frogs and toads and the hind legs of rabbits, he had rendered these parts anresthetic, and he obtained (he states) similar results in the human subject from keeping his finger immersed in anæsthetic fluids for half an hour or an hour. In one case where the operation for artificial pupil was to be undergone, he had (he mentions) rendered the parts nearly insensible by applying to the eye for twenty minutes previously a small quantity of the vapour of chloroform.
This naturally leads us on to the cansideration of the second and most important subject-viz., the artificial production of,

$$
\text { 2.- Local A nosthesia in the Human Subject. }
$$

In a previous paragraph I have already alluded to some experiments on the production of local anæsthesia in the gums, by rubbing them with prussic acid. Early in the present year I was led to make a variety of experiments on this subject, in consequence of being assured, on what I believed to be satisfactory evidence, that a dentist at Limoges, in France, M. Pernot, had the power of extracting teeth with little or no pain, in consequence of personally rubbing some obtunding agent on the gums. I tried at the time a great variety of substances in order to obtain this local anæsthesia, such as various ethers, bisulphuret of carbon, benzin, aconite, \&c. Of all the agents employed, the effect of prussic acid was most decided and complete; any part of the gum rubbed by it speedily became benumbed and insensible, but the resulting degree of anæsthesia was by no means sufficient for the purpose required. The results of these experiments were stated orally to the Edinburgh Medico-Chirurgical Society, at their meeting on the 16 th of February.

Before that date I had met with one instance in which local anæesthesia of the human hand had been produced in a young lady, in consequence of her accidentally holding in it for a considerable time a scent-bottle, containing some chloro. form. I tried at various times to produce a similar result in myself and in others, by keeping a hand for a short time wrapt in a napkin, soaked in chloroform and other anæsthetic agents, but with, indeed, little or no appreciable success, till I nsed the vapour of chloroform raised by heat-the hand, for the purpose, being immersed in a deep jar, in which a small quantity of chloroform was poured, the jar placed in a basin of water, of the temperature of $150^{\circ}$ or upwards, and the wrist or forearm being, at the same time, surrounded by handkerchiefs, so as to prevent the escape of the vapour. In the last number of the Monthly Journal, (p. 48,) these experiments are noticed, and it is correctly stated, that the degree of local anzesthesia of the human hand, which I had been thus able to produce, is only " partial, and perhaps super. ficial."

A number of circumstances influence, however, the effect and degree of it; and as I have made a considerable variety of experiments, both upon myself and upon others, in order to aseertain these points, I will shortly state the results. I. Tet me premise, that in the experiments upon which the following results are founded, the hands of the same individual were generally held simultaneously in two jars, differently arranged in regard to material or otherwise, in order to make two different and comparative experiments at the same time; and the relative degree of ancesthesia in each hand was ascertained during the experiment by pricking the fingers with the thumb-nail, without removing the hand from the jar. After they were removed, these and other more severe measures were used with the same view, as tests of the degree of anæesthesia.

1. When the hand is exposed to an anæsthetic vapour, it betimes presents the sensations of a limb benumbed by com. pression of the nerves - the sensations, in fact, of partial paralysis. Usually after a short time a glowing or burning feeling is perceived in the parts most exposed, and gradually there supervenes a sensation of thrilling and prickling, (like a limb asleep,) which deepens more and more. The hand at last feels stiff and clumsy, and as if enlarged, and painful impres. sions, as pricking, pinching, \&c., are felt less and less. The skin becomes red. After the hand is removed from the vapour, it is generally a considerable time before its usual normal feelings are restored. The nerves of motion are usually, apparently, as much affected as the nerves of sensation.

2. The vapour of chloroform proved stronger than any other that was tried. When one hand, for instance, was inmersed in a jar containing the vapour of sulphuric ether, and the other hand in a jar containing the vapour of chloroform, (both jars containing similar quantities, and subjected to the same degree of heat, ) the hand in the chlorotorm jar was both more speedily and more deeply affected than the other. In addition to the vapour of chloroform and ether, I tried comparative experiments with the vapours of aldehyde, bisulphuret of carbon, iodide of methyle, \&c. The aldehyde had little or no effect of any kind. The iodide of methyle produced a very severe burning sensation, and left the hand intensely red for many hours afterwards, but with no marked anæsthetic influence. Among several of us that tried the vapour of bisulphuret of carbon, only one bore it for any 
great length of time, (about an hour,) and in him it did not render the hand anæsthetic in any very appreciable degree. In myself and others the sensation of heat and burning soon became so utterly intolerable as to force us to withdraw the hand.

3. The anæsthetic effect is increased both in rapidity and in degree by immersing the hand with the cuticle softened and moist. When one hand, for instance, is immersed without any preparation, and the other is prepared by being bathed and fomented for ten or twenty minutes previously, the latter almost immediately begins to tingle under exposure to the vapour, the dry hand not for some minutes. The degree of anpesthesia is also ultimately deeper in the moistened hand.

4. The hand when plunged in liquid chloroform is usually somewhat more deeply apathized than the other hand simultaneously held in the vapour of chloroform. This was the more general result with those who tried the experiment; but in some, the chloroform vapour was as anesthetic or more so than the liquid. Few persons can keep the hand for any adequate length of time in liquid chloroform; the sensation of burning becomes so intense and painful as to force them to withdraw in a very few minutes. On one occasion, I held my hand for upwards of an hour in liquid chloroform without the part being more deeply apathized than it would have been by exposure to the vapour. One of my pupils, Mr. Adam, held his hand in the liquid chloroform for upwards of two hours; no great degree of local ansesthesia resulted. In these cases, in which the hand was long steeped in liquid chloroform, the sensation of burning returned severely from time to time, as if in waves, during the experiment; and on removing it from the jar, the feelings of heat were temporarily aggravated. The normal sensibility of the parts speedily returned, and were completely restored within a few minutes in all, but the skin sometimes remained red and injected for a longer period.

5. The degree of delicacy of skin in the person or part exposed to the anæsthetic vapour influences the result. In females, I have seen the degree of the local anresthesia of the hand, that was produced, much greater and deeper than I could ever render it in the male subject. In applying the chloroform vapour in small cupping-glasses \&c. to different parts of the body, as the insides of the arms \&c., the resulting degree of local anasthesia seemed, in a great measure regulated by the tenuity of the skin of the part experimented upon. The skin of the axilla seems too tender to allow of the vapour being applied for a length of time sufficient to produce anasthesia. One of my students, who kept both his lower extremities enveloped in strong chloroform vapour for three continuous hours, felt no appreciable local anasthetic effect from it.

6. When strong chloroform vapour is locally applied to mucous surfaces, the attendant sensations of heat and smarting are too severe to allow of its sufficient continuance. At least, this is the result that $I$ have obtained by applying it with small glasses to the insides of the lips, the tongue, and eye Mr. Nunneley states, as we have already mentioned, that before operating on a difficult case of artificial pupil, he had applied for twenty minutes a small quantity of the vapour of chloroform to the eye, by means of a small jar which accurately fitted the orbit, with the effect of rendering the parts nearly insensible. Dr. Duncan and myself have several times tried to repeat this experiment upon ourselves, but in none of the trials which we made, with the eye either shut or open, could we endure the burning action of the vapour upon the part above two or three minutes, and with no other result except always rendering the eye experimented on red and injected, and suffused with tears: *

7. The degree of anæesthesia produced in a limb, by exposure of it to the strong vapour of chloroform, does not, in general, perceptibly increase after fifteen or twenty minutes.

* I have tried the application of various anæsthetic gases and vapours to the vagina in cases of vaginal irritation and neuralgia, but hitherto without much success. The stronger forms cannot be borne. I was induced to try them in consequence of the following curious statement regarding carbonic acid, published by Dr. Periera, (Materia Medica, vol. i. p. 155.) "A lady who had suffered a considerable time from some uterine affection, and had derived no relief from the treatment adopted, was advised to consult a physician in Italy, (Dr. Rossi.) After he had exammed the condition of the uterus, he assured her there was no organic disease, but merely a considerable degree of irritation, for which he proposed to employ carbonic acid as a sedative. This was done by means of a pipe and tube communicating with a gasometer situated in another room. The patient ob the doctor's house, on account of the pain experienced in to be carried to it in perfect ease. On her return to England, she bad a relapse of the com plaint, and auplied to Dr. Clutterbuck to know whether she could have the same remedy applied in London, in order to save her the necessity of returning to Italy.
The same sensations continue if the hand is still retained in the jar; but an increased length of exposure does not, after a time, produce a corresponding degree of local insensibility.

But the degree of local anæesthesia produced in the human. hand or skin, by exposing it to the local action of the vapour of chloroform, has never, in my experiments, been by any means so perfect and complete as to annul the pain of any severe operation, such as deep incision or the amputation of a finger. As compared with the other non-exposed hand, the chloroformed hand is generally rendered, to a marked amount less sensitive, but the insensibility is never, I fear, so deep and perfect as will save the patient from the pain of the surgeon's knife. In short, I entirely doubt whether, in the human subject, we shall ever be able to reduce the knowledge of the possible reduction of local anæsthesia to any practical purpose. It is principally interesting in a toxicological and physiological point of view, and in relation to the mode of action of anæsthetic agents.* Its bearings are more upon the theory than upon the practice of anosthesia.

These remarks relate necussarily to local ancesthesia, as capable of being produced by the anæesthetic agents with which we are at present acquainted. Others may, no doubt, yet be detected much more powerful than any we at present know, and their local application may enable us to effect the local anæesthesia desired. At the same time, this consummation even seems doubtful; for, perhaps, any agent possessing a deeper and more rapid anzesthetic local power would, by absorption, affect the system generally, it may be dangerously, before complete local insensibility of a part could be effected. Some time ago, in attempting to produce local anæesthesia in my hand, by exposing it to the vapour of hydrocyanic acid ere the hand was much or very perceptibly benumbed, $I$ began to feel the constitutional effects of the poison; my respiration became irregular, and I felt giddy and faint, when my assistant removed my hand from the jar. All due care was taken to prevent my breathing any of the vapour, and $I$ sat, during the experiment, in a current of air. I felt the benumbing influence of the acid extending from the hand upwards along the arm, a minute or two before the experiment was stopped.

I have tried long immersion of the hand in various gases as carbonic acid and common coal gas, (both powertul general anæsthetics when inhaled, without any effect. Chaptal however, alleges that he had felt the limbs plunged in carbonic acid much benumbed; and Collard do Montigny found that, when the general surface of his body was immersed in carbonic acid, (arrangements being made so that none of it was breathed,) giddiness, ringing in the ears, and the other symptoms produced by the action of this gas, supervened in eight or ten minutes, proving that it was absorbed. Davy felt the premonitory exhilaration of nitrous oxide gas, by exposing the surface of his body to it in the same way.

Chaussier enclosed the leg of a dog in a bag containing sulphuretted hydrogen, and found that he conld in this way in a few minutes, induce the very poisonous effects of the gas and similar experiments were repeated by Lebkuchner and Nysten, and my friend, Dr. Madden, on the rabbit \&c., with similar results. I have held my hand enclosed in a bag filled with vapour of sulphuretted hydrogen for about half an hour, without feeling any local effects.

The facts which I have stated seem, in the present state of our knowledge, to point to the following

\section{Conclusions.}

1. In animals belonging to the class of annelida, complete local and limited anæsthesia can be produced by the local and limited application of chloroform to individual parts of the body of the animal.

2. In Batrachian reptiles, the tail or an individual $\operatorname{limb}$ can be affected in the same way with local anæsthesia; but in addition, general anresthesia of the animal usually results in a short time, by the action of the chloroform through the exposed part.

3. In the smaller mammalia, a single limb, or even the lower or pelvic half of the body, can be rendered anasthetic

* Perhaps we shall be less surprised at the difference in the degree of local anresthesia capable of being produced in the lower animals, as compared with man, when we recollect the difference that exists between the struc ture and functions of their skins, and that of the human subject. "In animals whose skin is moist, and which possesses a very delicate cuticle, cutaneous absorption is a constant and important function. Such are frogs, salamanders, and similar animals. The experiments of Edwards frogs, salamanders, and similar anmals. The experiments of Edwards in their support." - See Jackson on Abscrption, in "American Cyclopodia of Practical Iedicine," No. 2, p. 115 . 
by local exposure of these parts to the influence of chloroform.

4. In the human subject, local anzesthesia of a part, as the hand, can be produced by exposing it to the strong vapour of chloroform; but the resulting degree of this local anosthesia is not sufficiently deep to allow the part to be cut or operated upon without pain.

5. Any agent possessing a stronger benumbing or anæsthetic influence would probably be dangerous, by its acting on the general economy before the local anæsthesia were established to a depth sufficient for operating.

6. Artificial local anæsthesia, from any known anæsthetic agents, seems objectionable in any part intended to be operated upon, in consequence of the vascular congestion and injection which attend upon and result from this local anæsthesia.

7. There are few operations in which there is not previously a broken surface, and the application of chloroform \&c. to such a surface would be far too painful to be endured.

Ediuburgh, 1848.

\section{ZRebietos.}

A. Dispensatory, or Commentary on the Pharmacopceias of Great Britain, \&c. By Robert Christison, M.D., V.P.R.S.E., Ordinary Physician to the Queen for Scotland, \&c. Second Edition, Revised, with a Supplement. Edinburgh: Black. London: Longmans and Co. 1848. 8ro. pp. 1003.

To the second edition of this standard work is added a Supplement on the most important new remedies which have come into use since 1841, consisting of notices of Gallic acid, the iodides of arsenic and mercury, sulphate of bebeerina, Carrara water, Indian hemp, chloroform, the citrates, tartrate, and lactate of iron, matico, cod-liver oil, amorphous quinine, pyroxylic spirit (naphtha?) iodide of sulphur, and the chloride and valerianate of zinc. Of Indian hemp, Professor Christison says:-

"Some cases of tetanus appear to have been cured in the East Indies by it; favourable cases have been reported also in this country; and my colleague, Professor Miller, had a case under his care which proved successful without any other important remedy. It has also been employed with success as an anodyne in chronic rheumatism, toothach, and other varieties of neuralgia. I have used it a good deal, and with decided success, in diseases at large, to obtain sleep. On the whole, it is a remedy which deserves a more extensive inquiry than any hitherto instituted." - p. 969.

And the following passages form a part of his summary concerning chloroform:-

"Chloroform is, in large doses, a narcotic poison, and in medicinal doses, a stimulant, sedative, anti-spasmodic, anodyne, and anøsthetic. Irritant effects have also been observed; but these are inconsiderable when it is pure." .... "So early as 1838 , Dr. Formby, of Liverpool, used it, on account of these properties, in hysteria; and in 1814, M. Guillot, of Paris, made use of it as an anti-spasmodic in asthma. No great attention, however, has been since paid to its actions and uses, when given in this manner, although there can be little doubt that it will prove an important remedy."-p. 971.

"Since its first recommendation by Dr. Simpson, it has been extensively used in this city, in the way of inhalation, to subdue the sufferings of child-bearing. Its effect is perfect, and may be maintained uninterruptedly for many hours, without influencing the frequency or force of the uterine con. tractions, and witbout any eventual harm. It is only when the deepest coma, with suffocative stertor, is brought on, that the uterine contractions are apt to be arrested for a time, a property which may be taken advantage of to facilitate the operation of turning. I have used it with great advantage in the same manner, to arrest hiccup, even during fatal peritonitis, and to put an end to the paroxysm of tic dolonreux. Others have found it efficacious in asthma, hysteria, chronic vomiting, and delirium tremens. It has also been found of service occasionally as a hypnotic in the noisy forms of chronic insanity, and as a temporary measure, it has proved most serviceable in the removal of obstreperous lunatics from one place to another." ...... " Innumerable chloroform inhalers have been contrived in London and Paris, but nothing is so convenient as a small muslin or silk handkerchief, loosely twisted into the form of a bird's nest; no other apparatus is used in Edinburgh, and no inhaler can be more efficacious."-p. 973.

Concerning cod-liver oil, it is stated:-

"It acts as an alterative, improving the complexion, and tending remarkably to increase the deposition of fat in the cellular tissue." ...... "Gout, rachitis, caries, and tabes mesenterica, are also said to have yielded to it. Its efficacy in many of these obstinate diseases has been exaggerated by its admirers. But there is no doubt that it is occasionally serviceable, and especially in strumous affections of all sorts." -pp. 977,978 .

The preface may be quoted, for the author's statement as to differences between this and the former edition, and for other reasons.

"The body of the work, although not increased in size, has been greatly altered by numerous additions and alterations. For some of the corrections, the author is indebted to Mr. Richard Phillips, who, with a pertinacity of criticism unexampled in these days, has, during several years, exercised his censorship on the book from time to time, in three distinct periodicals, and in an express publication. A Dispensatory being no fit field for controversy, the author has been content with silently adopting or rejecting the proposed corrections, according as they were felt to be just or unjust, reserving till the present opportunity the expression, once for all, of his sense of the uncommon pains and trouble which have been taken by Mr. Phillips."-Preface.

The sarcasm, though smart, is good-humoured; and Dr. Christison's "silent" testimony is significant that "a pertinacity of criticism" may not be without good results, even when exercised upon works of the highest character.

The book is handsome and cheap.

The Cyclopecdia of Anatomy and Physiology. Edited by R. B. TODD, M.D., F.R.S., \&c. Part XXXI. pp. 112. Longmans and Co. May, 1848.

WE have to congratulate our readers, and, in particular, those of them who happen to be subscribers to the above work, upon the appearance of a new Part, and one which has, unlike several of its predecessors, followed closely upon a previous one. We hope that in this symptom of a fresh impetus given to the work, we shall not be disappointed; that the succession of other Parts in due order will not be delayed; for the delay and the irregularity which have attended most of those hitherto produced have very much compromised the value of the publication.

The true secret of the tardy appearance of the several articles, and of the prolongation of the publication over such a lapse of time, appears from the note to the article "Ren," in the present number. The word ren sounds curiously in our ears, not being in common use; but it was an editorial device to postpone the article "Kidney," which ought to have appeared long since, in accordance with the plan of the alphabetical arrangement of subjects adopted. Not that the learned editor is to be blamed in this matter; for, from the note alluded to, it appears that the article on the kidney has been assigned to two several gentlemen, previously to its falling into the hands of Dr. G. Johnson, its present writer; and that both those gentlemen failed in their engagement to produce it. We cannot too strongly decry such conduct as is here apparent. A moral wrong-a wrong both to the editor and to the subscribers-has been done.

We trust that the editor will devote all his energy and his official influence to ensure the speedy completion of this national cyclopredia,-otherwise the days of many of his contributors and subscribers will be numbered ere the last Part of the work issues from the printer's hands. We perceive that the next part is advertised to appear in August.

Of the contents of this thirty-first number we can speak very favourably. Dr. Walshe brings to a conclusion his essay on "Adventitious Products." Then follow the articles "Prostate," by Mr. Adams, of the London Hospital ; "Protein," by Mr. J. E. Bowman, of King's College; and "Pteropoda," by 